\title{
Complete situs inversus and broad thumbs and big toes with postaxial polydactyly
}

\author{
Andrew E Czeizel, Péter Göblyös
}

Department of Human

Genetics and

Teratology, National Institute of Public Health-WHO

Collaborating Centre for the Community

Control of Hereditary

Diseases, Gyáli út 2-6, 1097 Budapest,

Hungary

A E Czeizel

Department of

Radiology, National

Institute of

Haematology and

Immunology,

Budapest, Hungary

P Göblyös

Correspondence to:

Dr Czeizel.

Received 4 February 1997 Revised version accepted for publication 22 May 1997

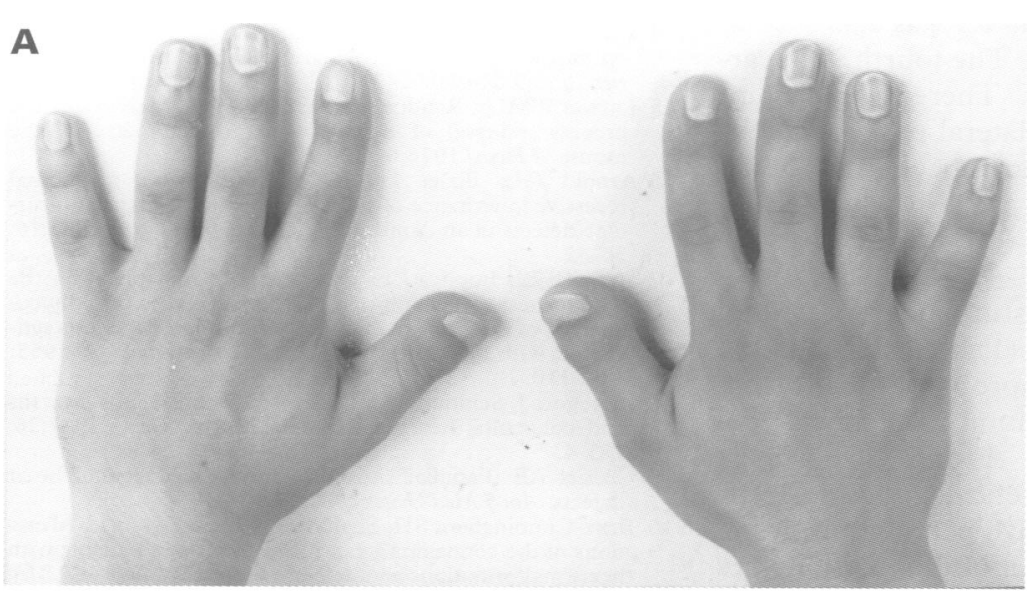

B

\begin{abstract}
A healthy, non-consanguineous couple had a son with complete situs inversus viscerum (including dextrocardia but without other cardiac defects), broad thumbs and big toes, postaxial polydactyly, average intelligence and length proportion of the extremities, and a normal face. The common cause of these defects may have a role in the origin of sidedness and symmetry in morphogenesis.
\end{abstract}

(F Med Genet 1997;34:1033-1034)

Keywords: situs inversus; broad thumbs and big toes; polydactyly; lateralisation

The development of sidedness and defects in lateralisation leading to the failure of normal symmetry in morphogenesis is an interesting basic question of organogenesis. ${ }^{1}$ As far as we know, the combination of complete situs inversus, bilateral broad thumbs and big toes, and bilateral postaxial polydactyly has not been published previously. Thus, the purpose of this case report is to contribute a new case to the topic of laterality.

\section{Case report}

A healthy couple visited our Genetic Counselling Clinic in 1982 with their son, born in 1974, who had a complex developmental disturbance. The parents were not consanguineous, their family history was negative, and they had no other child. The proband was born at term after an uncomplicated pregnancy weighing $3200 \mathrm{~g}$. His broad thumbs and big toes, bilateral postaxial skin tag polydactyly of the hands, and unilateral polydactyly of the left foot were noted immediately and his extra digits were removed. His situs inversus viscerum (transposition of the liver, one spleen of normal size, and large intestines, the right testis hanging lower than the left unlike normal) with dextrocardia was detected later. The proband returned in 1996 to clarify the recurrence risk of his defect for his planned offspring. He had a normal height $(175 \mathrm{~cm})$ with average intelligence and weight $(70 \mathrm{~kg})$ without any disproportion of the extremities or facial dysmorphism. His dextrocardia with total situs inversus viscerum was confirmed, but other cardiological defects were excluded by echocardiography. His hands with broad thumbs and simian creases (fig 1) and his feet with broad big toes (fig 2) showed a characteristic radiographic pattern (figs 3 and 4). Both thumbs had broad metacarpals and phalanges and the terminal phalanges were shorter. The second and third fingers showed a slight ulnar deviation and the third metacarpal was a bit broader. The fourth and fifth metacarpals were shorter with broader proximal epiphyses. All but the first terminal phalanges were normal. The first and fifth metacarpals had a concave angulation. In the carpal bones there was an

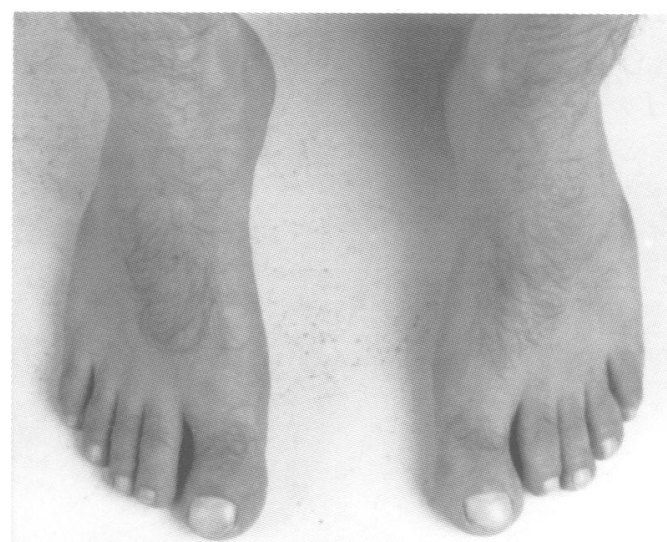

Figure 2 Feet of the proband. 


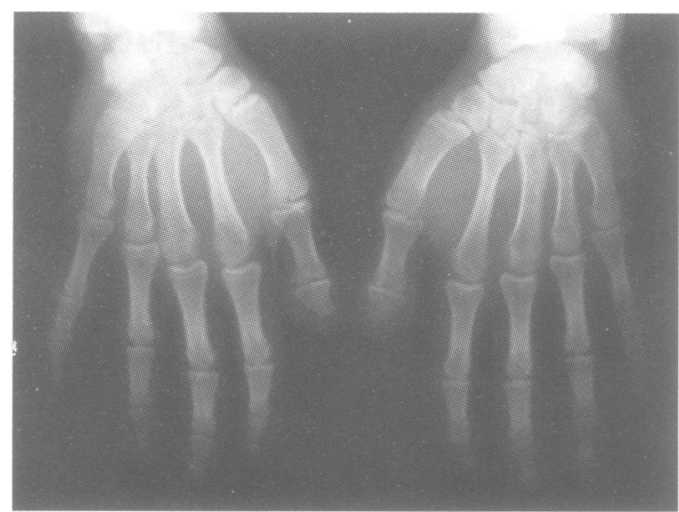

Figure $3 X$ ray of the hands.

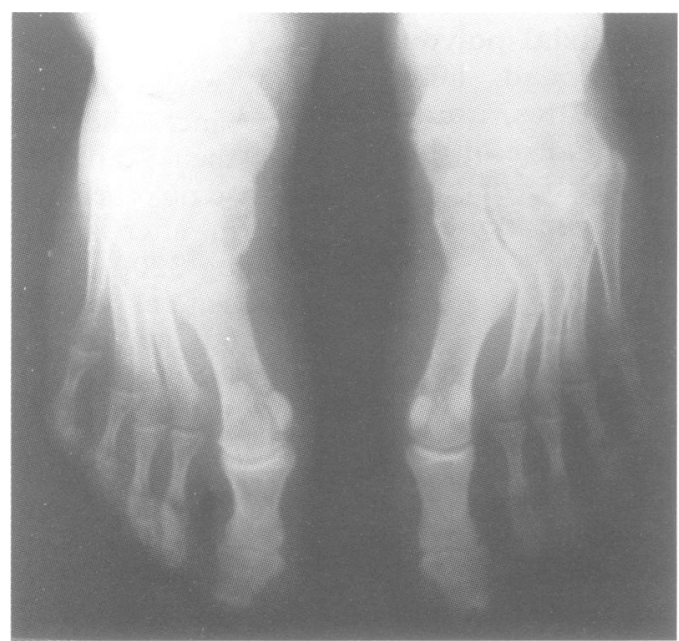

Figure $4 X$ ray of the feet.

extra os parastyloides. Both big toes had broad metatarsal and phalangeal bones with shorter terminal phalanges. The latter was also seen in the second and third toes. The fourth metacarpal bones were shorter. There was a joint between the medial and lateral parts of the os naviculare in both feet and he had bilateral, mild hallux valgus.

\section{Discussion}

The developmental disturbance described comprises three defects: (1) well formed skin tag postaxial polydactyly, probably type B (that is, pedunculated postminimi) which was removed. However, types A and B postaxial polydactyly may be genetically identical because these two forms have been found in the same families. ${ }^{23}$ (2) Broad thumbs and big toes predominated in the complex bone developmental disturbance of the hands and feet. (3) Complete situs inversus. There is evidence both in $\operatorname{man}^{4}$ and mouse ${ }^{5}$ that complete situs inversus and heterotaxy can represent a spec- trum of defects and the laterality sequence may include polysplenia, ${ }^{6}$ asplenia-hypoplastic spleen (Ivemark syndrome), ${ }^{7}$ and lung and cardiovascular malformations. ${ }^{89}$ Our proband does not have these defects (except dextrocardia as part of situs inversus, so the pattern seems to be an independent entity). Linkage of $\mathrm{X}$ linked laterality sequence to Xq24-q27.1 has been reported, ${ }^{10}$ while homozygous mutations in the connexin 43 gap junction gene have been found in patients with laterality defects. ${ }^{11}$

In the differential diagnosis, Kartagener's syndrome was unlikely because the proband had no defects of the cilia (nasal cilia were normal) and its consequences (sinusitis, bronchiectasia, etc). Sperm tails were not examined as the patient was non-compliant for religious reasons. Ellis-van Creveld syndrome was excluded because he had no short distal extremities, nail hypoplasia, cardiac defect, or reduced height. Rubinstein-Taybi syndrome was also excluded because of the lack of mental retardation and characteristic face, and Greig cephalopolysyndactyly syndrome because of the lack of syndactyly and peculiar skull shape.

In conclusion, the chance combination of the three developmental defects in the same person is unlikely, so a common cause can be expected. This cause may have a general importance in the origin of sidedness and symmetry in morphogenesis. ${ }^{12}$

1 Martin G. Pass the butter... Science 1996;274:203-4

2 Scott-Emuakpor AB, Madueke EDN. The study of genetic variation in Nigeria. II. The genetics of polydactyly. Hum Hered 1976;26:198-202.

3 Ventruto V, Theo G, Celona A, et al A and B postaxial polydactyly in two members of the same family. Clin Genet polydactyly in two

4 Polhemus DW, Schafer WB. Congenital absence of spleen: syndrome with atrioventricularis and situs inversus. Pediatrics 1952;9:696-708.

5 Layton WM, Jr. Random determination of a developmental process: reversal of normal visceral asymmetry in the mouse. $\mathcal{F}$ Hered 1976;67:336-8.

6 Arnold GL, Bixler D, Girod D. Probable autosoma recessive inheritance of polysplenia, situs inversus and cardiac defects in an Amish family. Am $\mathcal{F}$ Med Genet 1983;16: 35-42.

7 Ivemark BI. Implications of agenesis of the spleen on the pathogenesis of cono-truncal anomalies in childhood: analysis of the heart malformations in splenic agenesis syndrome, with fourteen new cases. Acta Paediatr Suppl 1955; 44:1-110.

8 Zlotogora J, Schimmel MS, Glaser Y. Familial situs inversus and congenital heart defects. Am $f$ Med Genet 1987;26: and cong.

9 Czeizel AE. Familial situs inversus and congenital heart defects. Am $\mathcal{F}$ Med Genet 1987;28:227-8.

10 Britz-Cunningham SH, Shah MM, Zuppa CW, et al. Mutations of the connexin 43 gap-junction gene in patients with heart malformations and defects of laterality. $N \mathrm{Engl} \mathcal{F} \mathrm{Med}$ 1995;332:1323-9.

11 Casey B, Devoto $\mathrm{M}$, Jones $\mathrm{KL}$, et al. Mapping a gene for familial situs abnormalities to human chromosome Xq24 q27.1. Nat Genet 1993;5:403-7.

12 Lowe LA, Supp DM, Sampath K, et al. Conserved left-right asymmetry of modal expression and alterations in murine situs inversus. Nature 1996;381:158-61. 